\title{
Analysis of conflicts of interest among authors and researchers of European clinical guidelines in cardiovascular medicine
}

\author{
Authors: Jonathan Hinton, ${ }^{A}$ Thomas Reeves ${ }^{B}$ and Benoy N Shah ${ }^{C}$
}

\section{Objectives}

We aimed to assess the frequency and nature of financial conflicts of interest among both the guideline committee authors and the authors of research studies used to support the European Society of Cardiology (ESC) guidelines.

Design

We evaluated the competing interests of the doctors that write five of the key ESC clinical practice guidelines (CPG): valvular heart disease (VHD), atrial fibrillation (AF), pericardial diseases (PD), heart failure (HF) and myocardial revascularisation (IHD). In addition, we examined the funding sources of studies cited in the recommendations that were related to pharmaceutical agents. If a study was sponsored by industry, the disclosures of all authors were reviewed to assess whether there was a financial conflict of interest with the study funder.

Results

In total, there were 603 recommendations (PD 112, VHD 111, HF 169, IHD 97 and AF 114) across the five guidelines, of which, 271 (45\% (PD 26, VHD 23, HF 72, IHD 84 and AF 66)) related to pharmaceutical agents. At least $80 \%$ of guideline committee authors, except for the PD guidelines, had a relevant financial conflict of interest, with the most frequent being a direct personal payment (68-82\%). Industry support for studies varied across the guidelines from $5 \%$ (PD) to $65 \%$ (IHD). If a study was funded by industry, authors were frequently (55-90\%) conflicted with the industry sponsor.

Conclusions

The majority of the doctors that write clinical guidelines have a relevant financial conflict of interest. In addition, industry sponsorship of studies is frequent, and authors are often conflicted with the study funder. We propose that physicians that write clinical guidelines should be free of such financial conflicts of interest to maintain scientific integrity and independence in the clinical guidelines.

Authors: A senior clinical fellow, Southampton General Hospital, Southampton, UK; ${ }^{\text {B }}$ Clinical fellow, Southampton General Hospital, Southampton, UK; ' Consultant cardiologist, Southampton General Hospital, Southampton, UK
KEYWORDS: conflict of interest, cardiology, industry

DOI: $10.7861 /$ clinmed.2020-0552

\section{Introduction}

Clinical practice guidelines (CPGs) are produced to optimise and standardise patient care by making evidence-based recommendations. These CPGs are developed by committees of experts within the field, which usually comprises a task force of 'authors' and document 'reviewers'. These practice-defining guidelines have substantial implications for clinicians, institutions that provide healthcare, pharmaceutical companies (industry) and, most importantly, patient care. ${ }^{1}$ Clinical recommendations within the guidelines are formed because of the guideline committee members' interpretation of available evidence. This creates two potential opportunities for industry to exert influence: the studies used as evidence and the way these studies are interpreted.

A conflict of interest (CoI) is "a set of circumstances that creates a risk that professional judgement or actions regarding a primary interest will be unduly influenced by a secondary interest'. ${ }^{2}$ While financial CoIs (FCoIs) are the focus of much research and commentary, there are also important non-financial CoIs, such as 'intellectual' CoIs.' Intellectual CoIs are "academic activities that create the potential for an attachment to a specific point of view that could unduly affect an individual's judgment about a specific recommendation.' These are often subtle and pervasive, making their assessment more challenging. ${ }^{1}$ Industry spends significant sums of money on relationships with healthcare organisations and professionals because FCoIs have been demonstrated to change practice. ${ }^{4,5}$ However, collaboration with industry facilitates development of new therapies and technologies that can improve patient care. ${ }^{6}$ It is therefore important not to abandon collaborative working with industry but to aim to strike a balance between joint endeavour and financial reward while preserving the integrity and independence of the processes involved in guideline development.

Given the importance of CPGs to clinical practice and the data demonstrating the potential impact that FCoIs have, we sought to review the frequency of these conflicts (among those that write the clinical guidelines as well as the research study authors) in relation to five of the European Society of Cardiology's (ESC) CPGs: valvular heart disease (VHD), atrial fibrillation (AF), pericardial diseases (PD), heart failure (HF) and myocardial revascularisation (IHD). ${ }^{7-11}$ 
Box 1. Types of financial conflict of interest with the pharmaceutical industry as defined by the European Society of Cardiology

Direct personal payment

Payment to institution

Receipt of royalty for intellectual property

Research funding (departmental/institutional)

Research funding (personal)

\section{Methods}

We first extracted the financial disclosures from the supplementary documentation for each of the five guidelines for all 220 guideline contributors (categorised by the ESC as authors / task force members and document reviewers). These disclosures are divided into five categories by the ESC (listed in Box 1). These declarations were reviewed and classed as an $\mathrm{FCoI}$ if these relationships were relevant to any part of the guideline; this included relationships with the pharmaceutical drug, device, imaging and any other industries that could benefit from recommendations within that guideline.

In the second aspect of the study, we analysed all recommendations related to pharmaceutical (medication) agents. For each of these recommendations, we noted the corresponding class of recommendation (CoR) and level of evidence (LoE). All references used to support these recommendations were then reviewed. We noted whether the studies were partly or fully funded by industry and, if so, the disclosures of all study authors were reviewed to ascertain whether the authors had a direct CoI with the industry study sponsor. If no disclosures were available for review, this was recorded.

\section{Results}

Disclosures were available for all 220 contributors to the five guidelines. The vast majority of guideline authors/reviewers had a direct FCoI with industry (illustrated in Fig 1). The most common relationship with industry in all the guidelines except PD was a direct personal payment, which was observed in $68-82 \%$ of

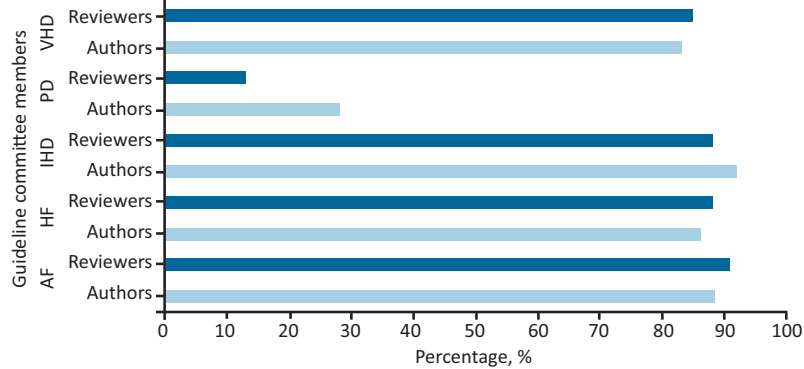

Fig 1. Frequency of any financial conflict of interest among guideline committee members. $\mathrm{AF}=$ atrial fibrillation; $\mathrm{HF}=$ heart failure; $\mathrm{IHD}=$ myocardial revascularisation; $\mathrm{PD}=$ pericardial diseases; $\mathrm{VHD}=$ valvular heart disease.

guideline authors and $69-76 \%$ of guideline document reviewers. Table 1 lists the breakdown of the FCoIs among the guideline committee members. As revealed in this table, in four of the five guidelines (IHD, AF, VHD and HF), the majority of guideline authors and reviewers received direct personal payments from industry; ranging from $68 \%$ (IHD) to as high as $82 \%$ (AF). Such payments were uncommon in the PD guideline.

In total, there were 603 recommendations (PD 112, VHD 111, HF 169, IHD 97 and AF 114) across the five guidelines, of which, 271 (45\% (PD 26, VHD 23, HF 72, IHD 84 and AF 66)) related to pharmaceutical agents. There were a small number of references for which no funding data was available (AF 5, HF 4, IHD 2, PD 4 and VHD 1), for analysis purposes, these were included in the total number of studies.

Industry sponsorship for the studies that were used to support the pharmaceutical recommendations was observed in a total of $152 / 360(42 \%)$ studies. This ranged from just $5 \%$ support in the PD guideline (1/20 studies) to $65 \%$ in the IHD guideline $(62 / 96$ studies). Industry support for studies related to pharmacological agents in the $\mathrm{AF}, \mathrm{HF}$ and $\mathrm{VHD}$ guidelines was present in $25 \%$ (30/121 studies), 46\% (51/112 studies) and 64\% (7/11 studies), respectively. There were no author disclosures available in a small number of studies funded by industry (AF 8, HF 12, IHD 12, PD 0

\begin{tabular}{|c|c|c|c|c|c|c|c|}
\hline Guideline & $\begin{array}{l}\text { Committee } \\
\text { member }\end{array}$ & $\mathrm{n}$ & $\begin{array}{l}\text { Direct personal } \\
\text { payment (\%) }\end{array}$ & $\begin{array}{l}\text { Payment } \\
\text { to their } \\
\text { institution (\%) }\end{array}$ & $\begin{array}{l}\text { Royalty from } \\
\text { intellectual } \\
\text { property (\%) }\end{array}$ & $\begin{array}{l}\text { Research funding } \\
\text { (departmental/ } \\
\text { institutional) (\%) }\end{array}$ & $\begin{array}{l}\text { Research } \\
\text { funding } \\
\text { (personal) (\%) }\end{array}$ \\
\hline \multirow[t]{2}{*}{ IHD } & Authors & 25 & 68 & 28 & 0 & 60 & 8 \\
\hline & Reviewers & 32 & 69 & 34 & 3 & 50 & 3 \\
\hline \multirow[t]{2}{*}{$\mathrm{AF}$} & Authors & 17 & 82 & 41 & 0 & 47 & 0 \\
\hline & Reviewers & 33 & 76 & 42 & 6 & 41 & 3 \\
\hline \multirow[t]{2}{*}{ PD } & Authors & 18 & 22 & 0 & 0 & 28 & 6 \\
\hline & Reviewers & 31 & 10 & 0 & 0 & 13 & 0 \\
\hline \multirow[t]{2}{*}{ VHD } & Authors & 18 & 72 & 39 & 6 & 17 & 0 \\
\hline & Reviewers & 34 & 75 & 32 & 0 & 24 & 0 \\
\hline \multirow[t]{2}{*}{ HF } & Authors & 21 & 76 & 38 & 0 & 52 & 0 \\
\hline & Reviewers & 42 & 76 & 31 & 2 & 50 & 2 \\
\hline
\end{tabular}

$\mathrm{AF}=$ atrial fibrillation; $\mathrm{HF}=$ heart failure; $\mathrm{IHD}=$ myocardial revascularisation; $\mathrm{PD}=$ pericardial diseases; $\mathrm{VHD}=$ valvular heart disease 


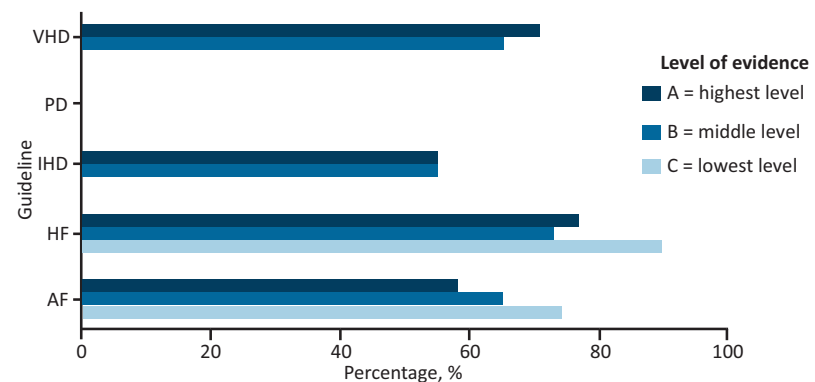

Fig 2. Percentage of authors with a financial conflict of interest with the study funder by guideline and level of evidence. $A F=$ atrial fibrillation; $\mathrm{HF}=$ heart failure; $\mathrm{IHD}=$ myocardial revascularisation; $\mathrm{PD}=$ pericardial diseases; $\mathrm{VHD}=$ valvular heart disease

and VHD 0). Fig 2 demonstrates that, except for PD, authors of these studies frequently had an FCoI with the industry sponsor, irrespective of the level of evidence of the study. Indeed, in the HF and $\mathrm{AF}$ guidelines, the vast majority of authors of studies cited in the guidelines at the lowest level of evidence (level of evidence C) had relevant financial conflicts with study the sponsors.

\section{Discussion}

There are two principal findings of our study. The first is that financial conflicts are extremely prevalent among the individuals that write five of the key ESC clinical guidelines. The second major finding is that, in four of the five guidelines we analysed, most authors of studies cited in support of pharmaceutical recommendations also had a direct FCoI with the study sponsor.
We believe that this is the first such analysis of key practice guidelines issued by a major international cardiovascular organisation, but our results are consistent with studies examining this issue in other areas of medicine. FCoIs have been frequently reported in CPG committee members across a range of specialties. ${ }^{12-14}$ This observation is likely to be an underestimate because FCoIs are often both under and inaccurately reported. ${ }^{12,13,15}$ Interestingly, authors of government-sponsored CPGs are less likely to have a direct FCoI compared with other sources of CPGs. ${ }^{12}$ Neuman et al analysed 14 CPGs related to diabetes and dyslipidaemia published between 2000-2010. ${ }^{12}$ Panel members from government-sponsored CPGs were significantly less likely to have a CoI compared to CPGs issued by non-governmental sources $(16 \%$ vs $69 \%$; p 0.001$) .^{12}$ George et al analysed two $\mathrm{CPG}$ related to management of idiopathic thrombocytopenic purpura (ITP). ${ }^{14}$ One CPG was issued as an international consensus report (ICR) and was supported by companies that manufacture products used in the treatment of ITP. The majority (73\%) of ICR panel members had financial CoIs with associated industries. A second CPG was issued by the American Society of Hematology (ASH) who chose panel members based upon a lack of competing interests. The authors found that the ICR panel produced considerably stronger recommendations for the use of agents manufactured by companies from which panel members had received financial support than the authors of the $\mathrm{ASH}$-sponsored CPG, demonstrating that CoI among CPG authors influences recommendations. ${ }^{14}$ Of further concern, bias has been shown often to result in an overestimation of benefit and to trivialise harm. ${ }^{1,14}$

Our study does, however, highlight that at least $10 \%$ of guideline committee members had no FCoIs. These data support the observation that there is a body of experts available that do not have FCoIs who could be used for guideline committees. ${ }^{15}$ Further measures, as have been adopted by both the National Institute for

Table 2. Classification of conflict of interest and action taken in the American College of Physicians' guidance for management of competing interests among guideline authors ${ }^{17}$

Level of CoI

Definition

High

Moderate

Low

Any active relationship (financial or otherwise) with a high-risk entity, which the CGC defines as an entity that has a direct financial stake in the clinical conclusions of a guideline or guidance statement.

Most frequently an intellectual interest that is clinically relevant to the guideline topic. Intellectual CoIs are previously formed conclusions that may leave a clinical guideline vulnerable to cognitive biases (eg confirmation bias or authority bias) and may result in indirect financial benefit related to career advancement.

Intellectual interest only tangentially related to guideline topic or a previous high-level CoI which is now inactive

\section{Management of CoI}

Option 1: participant discontinues association if they are willing and able to do so (eg sell off stock in a pharmaceutical company). Once inactive, high-level COIs downgraded to low-level as opportunity for direct financial benefit has been eliminated.

Option 2: if participant is unwilling or unable to release the interest, they are restricted from involvement in guideline development (participation in discussions, voting on recommendations and authorship).

Option 3: participant may resign from the committee. Partial restriction: may participate in discussions but restricted from voting and authorship (recognised as a non-author contributor in final document).

No restrictions: may participate in discussions, serve as an author and vote on recommendations.

CGC = Clinical Guidelines Committee; CoI = conflict of interest 
Summary

What is known?

> Medical guidelines define clinical practice and, as such, have substantial implications for clinicians, patients, healthcare providers and the pharmaceutical industry.

$>$ Industry spends large amounts of money on relationships with the healthcare community. Furthermore, evidence suggests that clinicians are likely to change their prescribing habits as a result of these relationships.

\section{What is the question?}

$>$ How much influence does industry have upon the content of clinical guidelines in cardiology?

$>$ There were two key aims of this study:

$>$ to evaluate the frequency of conflicts of interest among the clinicians involved in the production of five ESC guidelines

$>$ to examine the role of industry in producing the evidence used to support the pharmaceutical recommendations in these guidelines.

\section{What was found?}

> Across five clinical practice guidelines from the ESC, guideline authors frequently had a relevant CoI, particularly direct personal payments.

> The evidence used to support the pharmaceutical recommendations was often supported by industry-funded studies.

> Authors of industry-funded studies frequently had a conflict of interest with the study funder.

\section{What is the implication for practice now?}

> Given that there are experts without relevant CoIs, we suggest that all guideline committees adopt an approach similar to NICE in preventing clinicians with relevant CoIs from serving on guideline development committees.

Health and Care Excellence (NICE) and recently by the American College of Physicians (ACP), can be used to grade the relevance of a FCoI for a particular guideline and potentially exclude those with significant FCoIs from partaking in discussion or voting upon recommendations (Table 2 ). ${ }^{16,17}$

The significantly lower prevalence of CoIs among study authors and guideline authors/reviewers in the PD guideline is not surprising, as the majority of pharmaceutical recommendations in PD relate to generic medications such as aspirin, non-steroidal anti-inflammatory drugs, corticosteroids and colchicine, for which industry has no pecuniary interest.

In common with previous studies and the observation that industry now provides the largest source of funding for clinical trials in the USA, our analysis has demonstrated that a significant proportion (up to $64 \%$ ) of studies used to support the ESC guidelines are either fully or partially funded by industry., 2,20 Furthermore, our study supports previous observations that the authors of these studies are frequently conflicted with the study funder. ${ }^{18,20-23}$ There is much evidence to suggest that studies are more likely to be positive and the objectivity of reporting is likely to be reduced when authors have an FCoI. ${ }^{23,24}$ These observations are likely to be an underestimate given that self-reporting of FCoIs is often inaccurate. ${ }^{22,25}$ Importantly there is no evidence to suggest that studies not supported by industry are of poorer quality. ${ }^{26}$

\section{Limitations}

This study focused on five guidelines which were chosen because they covered a broad range of clinical cardiology; it is, however, not possible to be certain that these findings are representative of other guidelines. This study is descriptive and therefore unable to assess whether the declared FCoIs resulted in changes in reporting and recommendations. It is not possible to corroborate the documented disclosures; this raises the possibility that we may have underestimated the magnitude of the issue. ${ }^{12,13,15,22,25}$ Finally, this study assessed for financial CoIs and not intellectual CoIs. This assessment is important but challenging because intellectual CoIs are often subtle and pervasive but also powerful motivators for research. ${ }^{27}$ The inclusion of a group of authors with different backgrounds may provide some balance to discussions and could be used as a strategy to reduce the influence of intellectual CoIs on CPGs. In addition, the recent ACP update on management of CoIs does have a method for dealing for non-financial CoIs (for example, a moderate-level CoI could be "an intellectual interest that might lead to cognitive bias or relationships with entities that might profit by association with the guidelines') and this leads to exclusions in authorship and voting for guidelines (though permits participation in discussions). ${ }^{17}$

\section{Conclusion}

Financial CoIs are frequent among doctors that author influential clinical practice guidelines, as well as among researchers that produce studies used to support recommendations for pharmaceutical agents in the guidelines.

\section{References}

1 Norris SL, Holmer HK, Ogden LA, Burda BU. Conflict of interest in clinical practice guideline development: a systematic review. PLOS One 2011;6:e25153.

2 Lo B, Field M. Conflict of interest in medical research, education, and practice, 1st edn. Washington: The National Academies Press, 2009.

3 Guyatt G, Akl EA, Hirsh ] et al. The vexing problem of guidelines and conflict of interest: a potential solution. Ann Intern Med 2010;152:738-41.

4 Stelfox HT, Chua G, O'Rourke K, Detsky AS. Conflict of interest in the debate over calcium-channel antagonists. N Engl J Med 1998:338:101-6.

5 Orlowski JP, Wateska L. The effects of pharmaceutical firm enticements on physician prescribing patterns. There's no such thing as a free lunch. Chest 1992;102:270-3.

6 Unruh L, Rice T, Rosenau PV, Barnes AJ. The 2013 cholesterol guideline controversy: Would better evidence prevent pharmaceuticalization? Health Policy 2016;120:797-808.

7 Adler Y, Charron P. The 2015 ESC Guidelines on the diagnosis and management of pericardial diseases. Eur Heart J 2015;36:2873-4.

8 Kirchhof P, Benussi S, Kotecha D et al. 2016 ESC Guidelines for the management of atrial fibrillation developed in collaboration with EACTS. Eur Heart J 2016;37:2893-962.

9 Windecker S, Kolh P, Alfonso F et al. 2014 ESC/EACTS Guidelines on myocardial revascularization: The Task Force on Myocardial Revascularization of the European Society of Cardiology (ESC) and the European Association for Cardio-Thoracic Surgery (EACTS) Developed with the special contribution of the European Association of Percutaneous Cardiovascular Interventions (EAPCI). Eur Heart J 2014:35:2541-619. 
10 Ponikowski P, Voors AA, Anker SD et al. 2016 ESC Guidelines for the diagnosis and treatment of acute and chronic heart failure: The Task Force for the diagnosis and treatment of acute and chronic heart failure of the European Society of Cardiology (ESC) Developed with the special contribution of the Heart Failure Association (HFA) of the ESC. Eur Heart J 2016;37:2129-200.

11 Baumgartner H, Falk V, Bax J] et al. 2017 ESC/EACTS Guidelines for the management of valvular heart disease. Eur Heart ] 2017:38:2739-91.

12 Neuman J, Korenstein D, Ross JS, Keyhani S. Prevalence of financial conflicts of interest among panel members producing clinical practice guidelines in Canada and United States: cross sectional study. BMJ 2011;343:d5621.

13 Bindslev JB, Schroll J, Gøtzsche PC, Lundh A. Underreporting of conflicts of interest in clinical practice guidelines: cross sectional study. BMC Med Ethics 2013;14:19.

14 George JN, Vesely SK, Woolf SH. Conflicts of interest and clinical recommendations: comparison of two concurrent clinical practice guidelines for primary immune thrombocytopenia developed by different methods. Am J Med Qual 2014;29:53-60.

15 Lenzer J, Hoffman JR, Furberg CD, Ioannidis JP, Group GPRW. Ensuring the integrity of clinical practice guidelines: a tool for protecting patients. BMJ 2013;347:f5535.

16 National Institute for Health and Care Excellence. Policy on declaring and managing interests for NICE advisory committees. NICE, 2019. www.nice.org.uk/Media/Default/About/Who-we-are/ Policies-and-procedures/declaration-of-interests-policy.pdf

17 Qaseem A, Wilt T], Clinical Guidelines Committee of the American College of Physicians. Disclosure of interests and management of conflicts of interest in clinical guidelines and guidance statements: methods from the Clinical Guidelines Committee of the American College of Physicians. Ann Intern Med 2019;171:354-61.

18 Riechelmann RP, Wang L, O'Carroll A, Krzyzanowska MK. Disclosure of conflicts of interest by authors of clinical trials and editorials in oncology. J Clin Oncol 2007;25:4642-7.
19 Riaz H, Raza S, Khan MS, Riaz IB, Krasuski RA. Impact of Funding Source on Clinical Trial Results Including Cardiovascular Outcome Trials. Am J Cardiol 2015;116:1944-7.

20 Aneja A, Esquitin R, Shah K et al. Authors' self-declared financial conflicts of interest do not impact the results of major cardiovascular trials. J Am Coll Cardiol 2013;61:1137-43.

21 Riaz H, Khan MS, Riaz IB et al. Conflicts of interest and outcomes of cardiovascular trials. Am J Cardiol 2016;117:858-60.

22 Weinfurt KP, Seils DM, Tzeng JP et al. Consistency of financial interest disclosures in the biomedical literature: the case of coronary stents. PLoS One 2008;3:e2128.

23 Kjaergard LL, Als-Nielsen B. Association between competing interests and authors' conclusions: epidemiological study of randomised clinical trials published in the BMJ. BMJ 2002;325:249.

24 Rochon PA, Sekeres M, Hoey ] et al. Investigator experiences with financial conflicts of interest in clinical trials. Trials 2011;12:9.

25 Califf RM. Conflicting information about conflict of interest. J Am Coll Cardiol 2013;61:1144-5.

26 Lexchin J, Bero LA, Djulbegovic B, Clark O. Pharmaceutical industry sponsorship and research outcome and quality: systematic review. BMJ 2003;326:1167-70.

27 Levinsky NG. Nonfinancial conflicts of interest in research. N Engl J Med 2002;347:759-61.

Address for correspondence: Dr Benoy N Shah, Cardiac Administration Offices, Level E North Wing, Southampton General Hospital, Tremona Road, Southampton, Hampshire S016 6YD, UK.

Email: benoy.shah@uhs.nhs.uk

Twitter: @dr_benoy_n_shah 